\title{
IRISFLORENTIN SUPPRESSES ALLERGIC INFLAMMATION IN MAST CELLS VIA REDUCING HISTAMINE RELEASE AND PRODUCTION OF PRO-INFLAMMATORY CYTOKINES
}

\author{
YUNXING LI* and FANYIN MENG
}

\author{
Marine College, Shandong University, Weihai, Shandong 264209, P. R. China
}

\begin{abstract}
Allergic diseases afflict many people worldwide. Allergic inflammation encompassing acute allergic reaction and chronic inflammatory response is the major pathogenesis. To discovery novel therapeutic approach for allergic diseases, we have evaluated the anti-allergic inflammatory effects of irisflorentin using RBL-2H3 cells. The results showed certain concentrations of irisflorentin could suppress histamine release and secretion of TNF- $\alpha$, IL- $1 \beta$ and IL-6. Further investigations indicated that the effects of irisflorentin were associated with a reduction of intracellular calcium, suppression of NF- $\kappa B$ signaling pathway and inhibition of caspase-1 activity. Therefore, the results of the current study demonstrated that irisflorentin can ameliorate mast cell-mediated allergic inflammation. These results can provide evidence for the discovery of novel therapy for allergic diseases and application of irisflorentin in practice.
\end{abstract}

Keywords: irisflorentin, allergic inflammation, mast cells, histamine, pro-inflammatory cytokines

In a developed country, about $25 \%$ of people suffer from allergic diseases including food allergy, atopic dermatitis, anaphylaxis, sinusitis, pruritus, and asthma (1). As the effector of allergic inflammation, mast cells play an important role in the pathophysiology of allergic diseases (2). On the surface of mast cells, there are Fc receptors (FceRI), which can bind immunoglobulin E (IgE) with high-affinity. After exposed to allergens, crosslinking of $\operatorname{IgE}$ bound to FcERI will be induced and result in the activation of mast cells through degranulation, which will lead to the extracellular release of preformed mediators including histamine stored in the cells' cytoplasmic granules (3). These events will cause vasodilation, increased vascular permeability with edema, and acute functional changes in affected organs (1). In addition to the acute allergic response, prolonged or repetitive exposure to allergens will give rise to edema, pain, warmth, and erythema due to the synthesis and secretion of chemokines and cytokines following activation of mast cells, which presents the chronic inflammatory response (4).

Nuclear factor $\kappa$-light-chain-enhancer of activated $\mathrm{B}$ cells factor $(\mathrm{NF}-\kappa \mathrm{B})$ is a crucial transcription factor regulating the expression of target genes encoding pro-inflammatory cytokines and chemokines such as tumor necrosis factor- $\alpha$ (TNF- $\alpha$ ), interleukin-1 $\beta$ (IL-1 $\beta$ ) and IL-6 (5). In most cells, $\mathrm{NF}-\kappa \mathrm{B}$ resides predominantly in cytoplasm in the form of an inactive complex with the inhibitory $\mathrm{I} \kappa \mathrm{B} \alpha$, which is the substrate of IKK (I $\mathrm{BB}$ kinase) (6). After exposure to stimuli, IKK is activated and phosphorylates downstream I $\mathrm{I} B \alpha$, which results in the degradation of $\mathrm{I} \kappa \mathrm{B} \alpha$ through ubiquitin-proteasome pathway and the release of $\mathrm{NF}-\kappa \mathrm{B}$ from the complex (7). Then the released NF- $\kappa \mathrm{B}$ translocates to nucleus and regulates the expression of target genes (8). Therefore, inhibition of NF- $\kappa \mathrm{B}$ can attenuate chronic allergic inflammation.<smiles>COc1cc(-c2coc3cc4c(c(OC)c3c2=O)OCO4)cc(OC)c1OC</smiles>

Figure 1. Chemical structure of irisflorentin

* Corresponding author: e-mail: lyxsdu@sina.cn 
Irisflorentin (Fig. 1) is an isoflavonoid found in Belamcanda chinensis (9) and Iris leptophylla Lingelsh (10). Previous pharmacological investigations have shown irisflorentin affords neuroprotection (11) and anti-inflammation (12). In addition, irisflorentin can attenuate lipopolysaccharide (LPS)stimulated maturation of mouse bone marrowderived dendritic cells and mouse contact hypersensitivity response (13). In our interest to search phytochemicals for the prevention of allergic diseases, we have investigated anti-allergic inflammatory effects of irisflorentin using rat basophilic leukemia 2H3 (RBL-2H3) cells, which were employed as a model for mast cell due to they can bind $\operatorname{IgE}$ to FceRI receptors and trigger subsequent downstream events, though they share some typical characteristics of both mast cells and basophils (14). Herein, we report the results and relevant mechanisms.

\section{MATERIALS AND METHODS}

\section{Chemicals and reagents}

Irisflorentin was purchased from Chengdu Derick Biotechnology Co., Ltd (Chengdu, China), which was obtained from the roots of Belamcanda chinensis. 3-(4,5-dimethyl-2-thiazolyl)-2,5-diphenyl-2-H-tetrazolium bromide (MTT), dimethyl sulfoxide (DMSO), anti-dinitrophenyl (DNP) $\operatorname{IgE}$ and DNP human serum albumin (HSA) were supplied by Sigma-Aldrich Inc (St. Louis, MO, USA). Dexamethasone was furnished by Dalian Meilun Biotechnology Co., Ltd (Dalian, China). Dulbecco's modified eagle medium (DMEM) and lipofectamine 2000 transfection reagent were obtained from Thermo Fisher Scientific Inc (Waltham, MA, USA). Fluo-3 AM, Caspase-1 assay kit and nuclear and cytosolic protein extraction kit as well as luciferase assay system including firefly luciferase reporter plasmid pNFkB-luc, renilla luciferase reporter vector plasmid pRL-SV40-C and dual-luciferase reporter gene assay kit were purchased from Beyotime Biotechnology Institute (Nantong, China). ELISA assay kits for TNF- $\alpha$, IL- $1 \beta$ and IL-6 were provided by Nanjing Jiancheng Bioengineering Institute (Nanjing, China). The primary antibodies including anti-p-NF- $\kappa \mathrm{B}$ (monoclonal antibody), anti-p-I $\kappa \mathrm{B} \alpha$ (polyclonal antibody) and anti-cleaved caspase-1 (polyclonal antibody) were purchased from Affinity Biosciences (Cincinnati, $\mathrm{OH}, \mathrm{USA}$ ).

\section{Cell culture and treatment}

RBL-2H3 cells were obtained from the Cell Bank of the Type Culture Collection of the Chinese
Academy of Sciences (Shanghai, China) and maintained in DMEM with $10 \%$ fetal bovine serum, 100 $\mathrm{U} / \mathrm{mL}$ penicillin and $100 \mu \mathrm{g} / \mathrm{mL}$ streptomycin at $37^{\circ} \mathrm{C}$ under the humidified $5 \% \mathrm{CO}_{2}$ condition. Then cells were sensitized with anti-DNP $\operatorname{IgE}(1 \mu \mathrm{g} / \mathrm{mL})$ for $16 \mathrm{~h}$ and treated with indicated concentrations of compound obtained $(0,0.5,5$ and $50 \mu \mathrm{M})$ prior to stimulation with of DNP-HSA $(0.5 \mu \mathrm{g} / \mathrm{mL})$. The cells in the control group were cultured under normal conditions.

\section{Cell viability}

MTT assay was used to reveal the cytotoxic effect of irisflorentin on RBL-2H3 cells. In Brief, cells were seeded in 96-well microplates at the density of $3 \times 10^{4}$ cells per well and pretreated with indicated irisflorentin $(0.1,0.5,1,5,10,50,100,200$, and $400 \mu \mathrm{M}$ ) or $0.1 \%$ DMSO. After incubation for $24 \mathrm{~h}, 0.5 \mathrm{mg} / \mathrm{mL}$ MTT solution was added into each well and incubated at $37^{\circ} \mathrm{C}$ for $4 \mathrm{~h}$. Then $100 \mathrm{~mL}$ DMSO was added to dissolve formazan crystals and the absorbance was determined at $570 \mathrm{~nm}$ on a microplate reader (Molecular Devices, Sunnyvale, CA, USA). The cell viability was expressed as the relative percentage of absorbance against that in the control group.

\section{Histamine release}

To assess the degranulation of mast cells, the histamine level in culture medium was measured using o-phthaldialdehyde fluorometric method according to the supplier's protocol. Briefly, RBL$2 \mathrm{H} 3$ cells were sensitized with anti-DNP $\operatorname{IgE}(10$ $\mu \mathrm{g} / \mathrm{mL}$ ) and incubated overnight. Then they were treated with indicated concentrations of the compound obtained $(0,0.5,5$ and $50 \mu \mathrm{M})$ for $30 \mathrm{~min}$ and stimulated by DNP-HSA $(0.5 \mu \mathrm{g} / \mathrm{mL})$. The incubated was implemented at $37^{\circ} \mathrm{C}$ for $2 \mathrm{~h}$. The cells were centrifuged at $400 \times \mathrm{g}$ for $5 \mathrm{~min}$. And $20 \mu \mathrm{L}$ supernatant was collected and transferred to the opaque 96-well microplate. After mixed with $200 \mu \mathrm{L}$ o-phthaldialdehyde solution, the fluorescence intensity was determined using a fluorescence microplate reader (Molecular Devices, Sunnyvale, CA, USA) and the excitation and emission wavelengths were set at $360 \mathrm{~nm}$ and $440 \mathrm{~nm}$, respectively.

\section{Intracellular calcium level}

The level of intracellular calcium was determined using the molecular fluorescence probe Fluo3 AM. RBL-2H3 cells were pre-incubated with 2 $\mu \mathrm{M}$ Fluo-3 $\mathrm{AM}$ at $37^{\circ} \mathrm{C}$ for $1 \mathrm{~h}$ and washed to remove the dye from the surface of cells. Cells were treated with the certain compound obtained at $37^{\circ} \mathrm{C}$ 
for 30 min prior to stimulation with DNP-HSA for 2 $\mathrm{h}$. The fluorescence intensity was recorded on a fluorescence microplate reader with excitation wavelength at $485 \mathrm{~nm}$ and emission wavelength at 520 $\mathrm{nm}$.

\section{Secretion of pro-inflammatory cytokines}

RBL-2H3 cells were treated above and centrifuged at $500 \times \mathrm{g}$ for $5 \mathrm{~min}$. Then the supernatant was collected as a sample for further analysis. The secretion of pro-inflammatory cytokines including TNF- $\alpha$, IL- $1 \beta$ and IL- 6 was monitored using ELISA kits following the supplier's instructions. The absorbance of each sample was recorded on a microplate reader at $450 \mathrm{~nm}$. The results were expressed as $\mathrm{pg} / \mathrm{mL}$ derived from standard curves.

\section{Caspase-1 activity}

Caspase-1 activity in RBL-2H3 cells was detected using a colorimetric assay kit according to

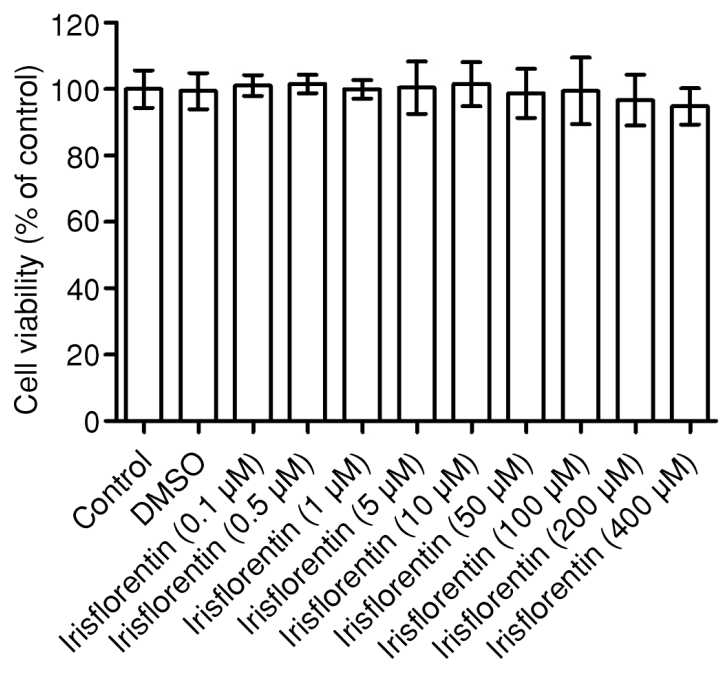

Figure 2. Effect of irisflorentin on the viability of RBL-2H3 cells

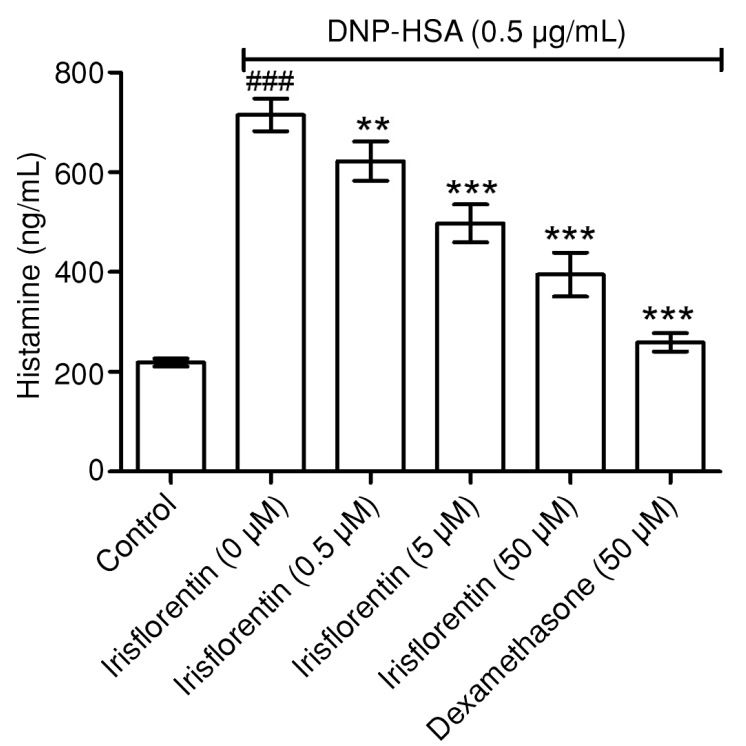

Figure 3. Irisflorentin reduces the release of histamine in RBL-2H3 cells stimulated by DNP-HSA. $\mathrm{n}=5$, \#\#\# $<0.001$ vs control group; $* * \mathrm{p}<0.01$ and $* * * \mathrm{p}<0.001$ vs irisflorentin $(0 \mu \mathrm{M})$ group 
the manufacturer's protocol. After treated as above, RBL-2H3 cells were lysed on ice for $15 \mathrm{~min}$ and centrifuged at $4^{\circ} \mathrm{C}$ and $16,000 \times \mathrm{g}$ for $10 \mathrm{~min}$. The supernatant was collected and incubated with the substrate Ac-YVAD- $p N A$ at $37^{\circ} \mathrm{C}$ for $1 \mathrm{~h}$. The absorbance was measured on the microplate reader at $405 \mathrm{~nm}$.

\section{NF-אB activation}

RBL-2H3 cells were co-transfected with 100 ng firefly luciferase reporter plasmid pNFkB-luc and $10 \mathrm{ng}$ renilla luciferase reporter vector plasmid
pRL-SV40-C per well. Transfection was carried out for $24 \mathrm{~h}$ using Lipofectamine 2000 following the supplier's instructions. Cells were treated with certain compound obtained prior to stimulation with DNP-HAS. Then the cells were washed with icecold saline buffer and lysed with lysis buffer. Luciferase activities were measured using the dualluciferase reporter gene assay kit with a GloMax-96 microplate luminometer (Promega, Madison, WI, USA). Data are normalized by firefly luciferase activity against that of renilla luciferase.

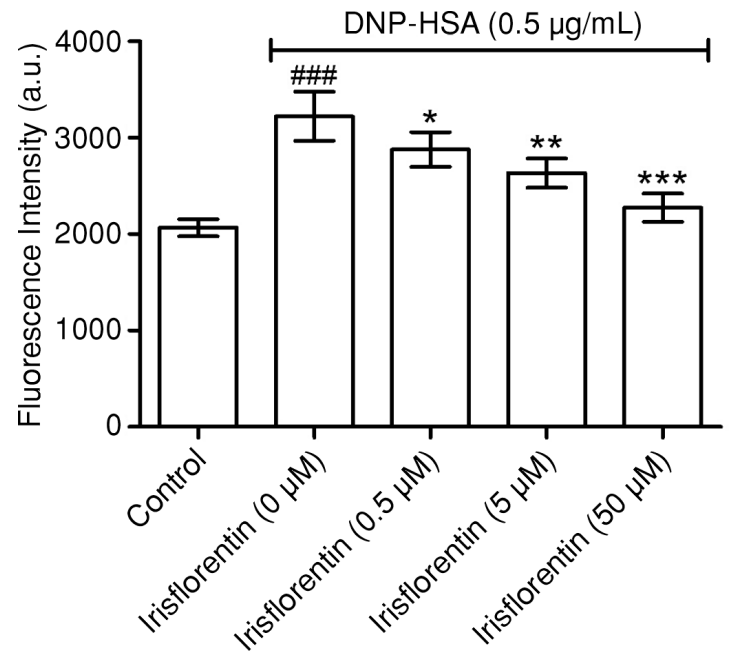

Figure 4. Irisflorentin decreases intracellular calcium level in RBL-2H3 cells stimulated by DNP-HSA. $\mathrm{n}=5$, \#\#\# $<0.001$ vs control group; ${ }^{*} \mathrm{p}<0.05, * * \mathrm{p}<0.01$ and $* * * \mathrm{p}<0.001$ vs irisflorentin $(0 \mu \mathrm{M})$ group

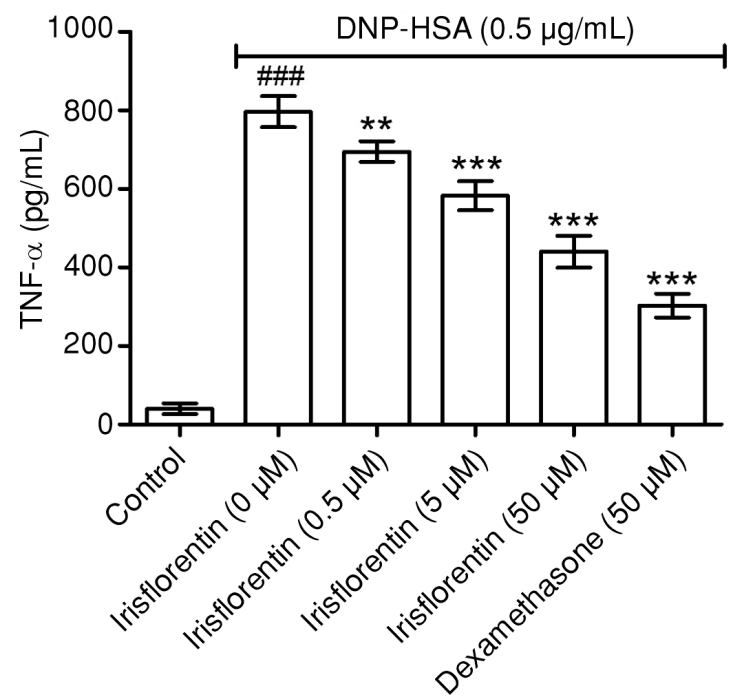

Figure 5. Irisflorentin supresses secretion of TNF- $\alpha$ in RBL-2H3 cells stimulated by DNP-HSA. $\mathrm{n}=5$, \#\#\# $<0.001$ vs control group; $* \mathrm{p}<0.05, * * \mathrm{p}<0.01$ and $* * * \mathrm{p}<0.001$ vs irisflorentin $(0 \mu \mathrm{M})$ group 


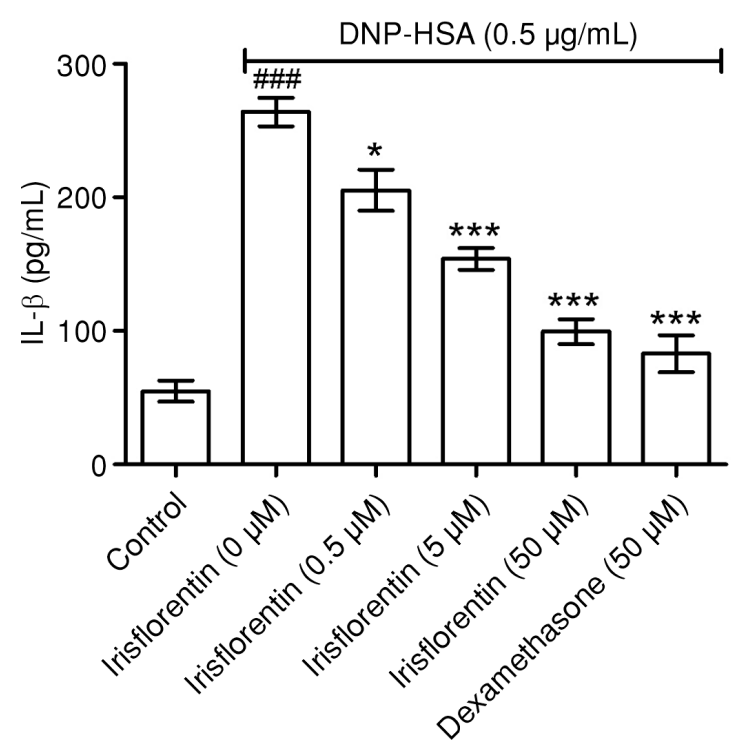

Figure 6. Irisflorentin inhibits secretion of IL-1â in RBL-2H3 cells stimulated by DNP-HSA. $n=5$, \#\#p $<0.001$ vs control group; ${ }^{*} \mathrm{p}<0.05$ and ${ }^{* * *} \mathrm{p}<0.001$ vs irisflorentin $(0 \mu \mathrm{M})$ group

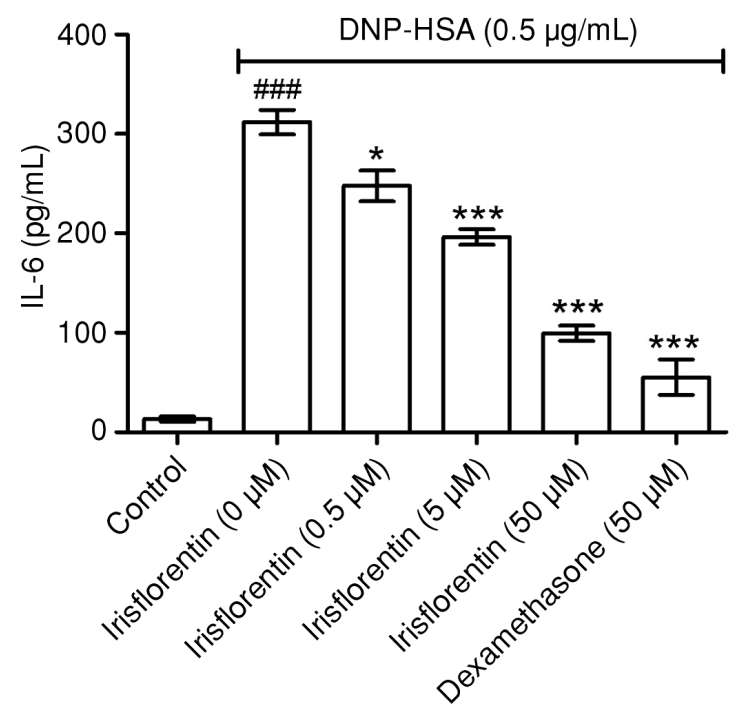

Figure 7. Irisflorentin diminishes secretion of IL-6 in RBL-2H3 cells stimulated by DNP-HSA. $n=5$, \#\# $<0.001$ vs control group; $* \mathrm{p}<0.05$ and $* * * \mathrm{p}<0.001$ vs irisflorentin $(0 \mu \mathrm{M})$ group

\section{Western blotting analysis}

After treated as above, the cytosolic and nuclear proteins in RBL-2H3 cells were extracted using the nuclear and cytosolic protein extraction kit following the supplier's protocol. Briefly, the cells were treated with $200 \mu \mathrm{L}$ buffer A solution containing PMFS in the kit and then subject to vortex for $5 \mathrm{~s}$. After incubation on ice for $10 \mathrm{~min}, 10 \mu \mathrm{L}$ buffer $B$ solution was added and vortex was performed for another $5 \mathrm{~s}$. After centrifugation at $12000 \times \mathrm{g}$ for 5 min, the supernatant was collected as cytosolic proteins. Then the pellet was mixed with $50 \mu \mathrm{L}$ buffer C solution containing PMSF and incubation was carried out on the ice for $30 \mathrm{~min}$. Following centrifugation at $12000 \times \mathrm{g}$ and $4^{\circ} \mathrm{C}$ for $10 \mathrm{~min}$, the supernatant was collected as nuclear protein for analysis.

The collected protein extracts were separated by electrophoresis on 10\% SDS-PAGE and transferred to a nitrocellulose membrane. The membranes were 
blocked with defatted milk at room temperature. The expression of activated $\mathrm{I} \kappa \mathrm{B} \alpha$, caspase- 1 and nuclear NF- $\kappa \mathrm{B}$ was detected using primary antibod-

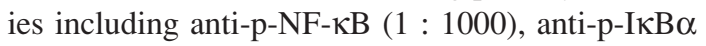
(1 : 1000) and anti-cleaved caspase-1 (1 : 1000). After washed three times with buffer solution including $0.1 \%$ Tween-20, the membranes were incubated with the corresponding secondary antibody $(1: 1000)$ conjugated to horseradish peroxidase in blocking solution at room temperature for $1 \mathrm{~h}$ and visualized by enzyme-link chemiluminescence (ELC) substrate. The bands can be measured by densitometric analysis using the free software ImageJ (NIH, Bethesda, MD, USA).

\section{Statistical analysis}

Experimental data were expressed as the mean \pm SEM. GraphPad Prism 5.0 (GraphPad Software, Inc., La Jolla, CA, USA) was used for statistical analysis. The experimental data from different groups were analyzed by one-way analysis of variance (one way ANOVA) followed by a Tukey test for multiple comparisons. Student's t-test was used for single comparisons. $\mathrm{p}<0.05$ was considered as statistical significance.

\section{RESULTS}

\section{Irisflorentin doesn't affect the cell viability}

To evaluate the effect of irisflorentin on cell viability, the cells were treated with irisflorentin. As shown in Figure 2, certain concentrations of irisflo- rentin (0.1-400 $\mu \mathrm{M})$, as well as DMSO, had no effect on the viability of RBL-2H3 cells compared with the control. These results gave the evidence to further explore the anti-allergic inflammatory effects of irisflorentin.

\section{Irisflorentin reduces histamine release in RBL- $2 \mathrm{H} 3$ cells}

After stimulated by DNP-HSA, it can be observed the histamine level was elevated in RBL$2 \mathrm{H} 3$ cells $(714.9 \pm 14.6 \mathrm{ng} / \mathrm{mL})$ compared to control group (218.9 $\pm 8.2 \mathrm{ng} / \mathrm{mL}, \mathrm{P}<0.001)$ (Fig. 3), which indicated the degranulation of mast cells occurred. In the presence of indicated Irisflorentin $(0.5,5$ and $50 \mu \mathrm{M})$, the extracellular histamine levels have been reduced significantly (622.2 \pm 17.6 , $497.7 \pm 16.9$ and $395.0 \pm 19.7 \mathrm{ng} / \mathrm{mL}$ ). These results indicated irisflorentin can attenuate acute allergy induced by DNP-HSA in RBL-2H3 cells.

\section{Irisflorentin decreases the intracellular calcium level in RBL-2H3 cells}

To further demonstrate the mechanism of irisflorentin reducing histamine release in RBL-2H3 cells, intracellular calcium has been detected. As shown in Figure 4, DNP-HSA can result in the elevation of intracellular calcium (3223.2 \pm 113.4$)$ by comparison with the control group (2067.6 \pm 87.7$)$. However, if treated with indicated irisflorentin beforehand, the intracellular calcium levels declined in a dose-dependent manner $(2877.4 \pm 80.7,2634.0$ \pm 68.2 and $2274.0 \pm 65.7$ ). These observations dis-

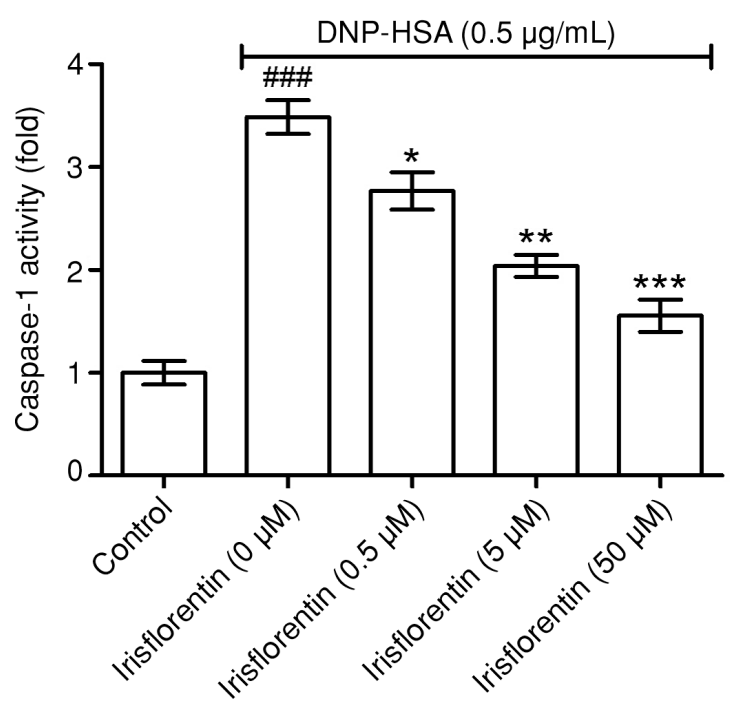

Figure 8. Irisflorentin inactivates caspase-1 in RBL-2H3 cells stimulated by DNP-HSA. $\mathrm{n}=5$, \#\#\# $<0.001$ vs control group; $* \mathrm{p}<0.05$, $* * \mathrm{p}<0.01$ and $* * * \mathrm{p}<0.001 \mathrm{vs}$ irisflorentin $(0 \mu \mathrm{M})$ group 


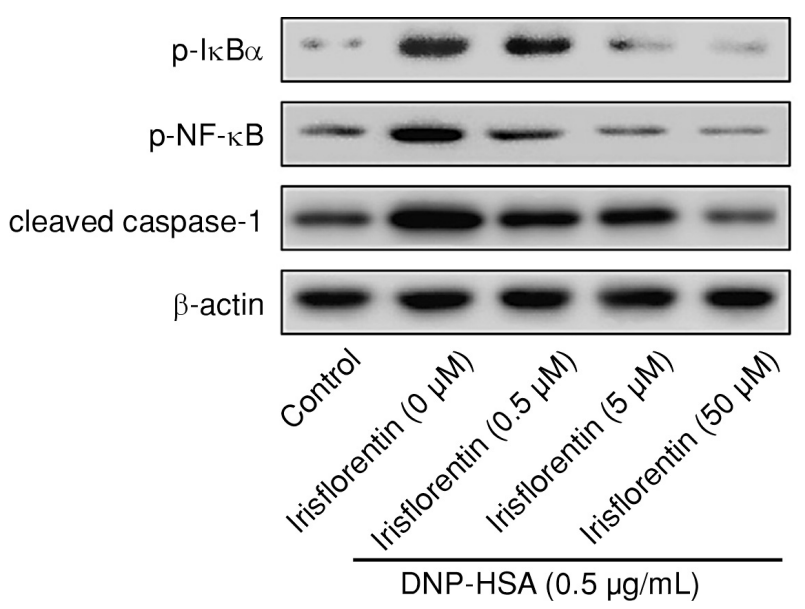

Figure 9. Western blot analysis for the expression of $\mathrm{p}-\mathrm{I} \kappa \mathrm{B} \alpha, \mathrm{p}-\mathrm{NF}-\kappa \mathrm{B}$ and cleaved caspase-1

closed the anti-allergic effect of irisflorentin involves inhibiting overload of intracellular calcium.

Irisflorentin suppresses the secretion of proinflammatory cytokines in RBL-2H3 cells

The anti-inflammatory effects of irisflorentin were evaluated through detecting the secretion of pro-inflammatory cytokines including TNF- $\alpha$, IL$1 \beta$, and IL- 6 in RBL-2H3 cells. As shown in Figure 5 , the secretion of TNF- $\alpha$ was elevated due to the stimulation of DNP-HSA in RBL-2H3 cells and reduced by irisflorentin significantly. Meanwhile, the increased IL- $1 \beta$ and IL- 6 after exposure to DNPHSA was decreased by irisflorentin in RBL-2H3 cells (Figs. 6 and 7). These results implied irisflorentin can suppress the inflammation in RBL-2H3 cells triggered by DNP-HSA.

Irisflorentin inhibits caspase-1 activity in RBL$2 \mathrm{H} 3$ cells

As the upstream regulator of some pro-inflammatory cytokines such as IL- $1 \beta$, the activity of caspase- 1 in RBL-2H3 cells was evaluated using colorimetric method. The result has shown DNP-HSA can activate caspase-1 obviously (Fig. 8). However, certain concentrations of irisflorentin can inhibit the activity in a dose-dependent manner. In addition, western blot analysis has also uncovered the expression of active caspase-1 (cleaved caspase-1) in RBL-2H3 cells was up-regulated by DNP-HSA, while irisflorentin can down-regulate it (Fig. 9). These facts demonstrate activation of caspase- 1 is involving the anti-allergic inflammation of irisflo- rentin in RBL-2H3 cells.

Irisflorentin inactivates $\mathrm{NF}-\mathrm{\kappa B}$ signaling pathway in RBL-2H3 cells

To further elucidate the mechanism of irisflorentin on the anti-inflammation in RBL-2H3 cells, the NF- $\kappa \mathrm{B}$ signaling pathway was investigated. Western blot analysis has revealed the stimulation of DNP-HSA in RBL-2H3 cells resulted in the up-regulation of phosphorylated I $\mathrm{I} B \alpha$ as well as phosphorylated $\mathrm{NF}-\kappa \mathrm{B}$, which indicated the activation of $\mathrm{NF}-\kappa \mathrm{B}$ signaling pathway. In the presence of certain irisflorentin, activated $\mathrm{I} \kappa \mathrm{B} \alpha$ and $\mathrm{NF}-\kappa \mathrm{B}$ were inhibited (Fig. 9). At the same time, dual-luciferase reporter assay has monitored the transcription activity of NF- $\mathrm{KB}$ in nuclei. RBL-2H3 cells were transiently transfected with $\mathrm{NF}-\kappa \mathrm{B}$ luciferase reporter and empty reporter vector. The relative luciferase activity was increased in RBL-2H3 cells stimulated by DNP-HSA, whereas irisflorentin reduced the activity (Fig. 10). These findings disclosed NF- $\kappa B$ signaling pathway was involved in the anti-allergic inflammation of irisflorentin in RBL-2H3 cells.

\section{DISCUSSION}

Allergic diseases are the undesirable adaptive reaction to exogenous allergens. Allergic inflammation plays a predominant role in the pathogenesis of allergic diseases. After exposure to extrinsic allergens, mast cells will be activated through IgE-associated acquired immune responses, which results in the acute allergy following histamine release from granules (15). Persistent or repetitive exposure to these allergens will lead to chronic inflammation 


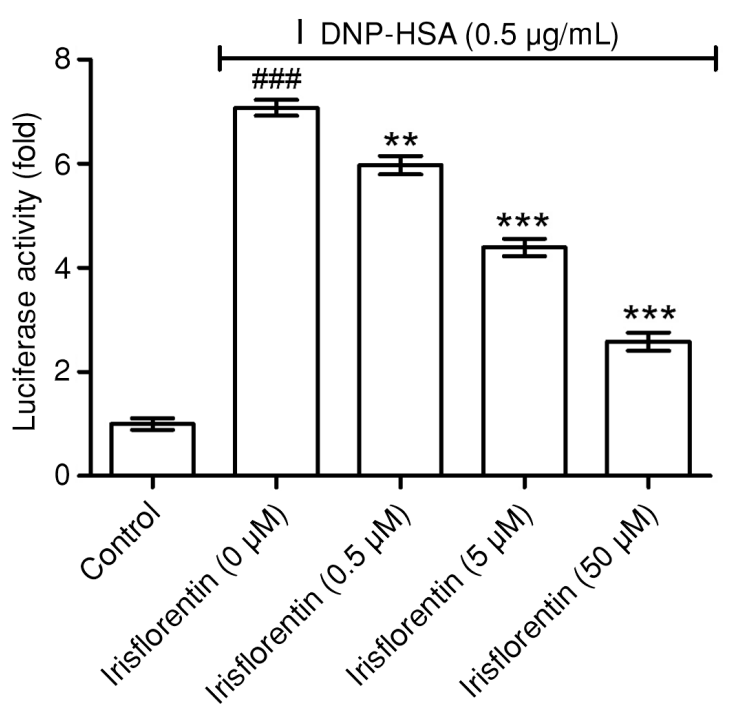

Figure 10. Irisflorentin down-regulates NF- $\mathrm{KB}$ transcription activity in nuclei of RBL-2H3 cells stimulated by DNP-HSA. $\mathrm{n}=5$, \#\#\# $<$ 0.001 vs control group; $* * \mathrm{p}<0.01$ and $* * * \mathrm{p}<0.001$ vs irisflorentin $(0 \mu \mathrm{M})$ group

due to the secretion of cytokines encompassing TNF- $\alpha$, IL-1 $\beta$ and IL-6 (1). Therefore, blocking allergic inflammation will provide effective therapy for allergic diseases. In the discovery of drugs targeting allergic diseases, phytochemicals have taken an important part such as galangin (16), chrysin (17) and chicoric acid (18). As the major phytochemical, irisflorentin was found in Belamcanda chinensis (9) and Iris leptophylla Lingelsh (10). Pharmacokinetic analysis has revealed after oral administration of irisflorentin $27.0 \mathrm{mg} / \mathrm{kg}$ in Belamcanda chinensis extract to rats, the maximum plasma concentration $\left(\mathrm{C}_{\max }\right)$ was $29.9 \pm 3.5 \mu \mathrm{g} / \mathrm{mL}$, time to maximum concentration $\left(\mathrm{T}_{\max }\right)$ was $0.25 \pm 0.0 \mathrm{~h}$, apparent elimination half-life time $\left(\mathrm{t}_{1 / 2}\right)$ was $3.48 \pm 0.37 \mathrm{~h}$, and area under the curve (AUC) was 52.42 $\pm 5.7 \mu \mathrm{g} / \mathrm{Lh}$ (19). In LPS-stimulated RAW 264.7 macrophages, irisflorentin reduced inducible nitric oxide synthase (iNOS) and the production of NO, and inhibited TNF- $\alpha$, IL-1 $\beta$ and IL-6, which indicated it afforded anti-inflammatory activity (12). Meanwhile, irisflorentin attenuated phenotypic and functional maturation of LPS-induced mouse bone marrow-derived dendritic cells and contact hypersensitivity responses of mouse skin (13). These facts gave us an insight that may be active in allergic inflammation, but the effects of irisflorentin in allergic inflammation have not been explored widely. Herein, we evaluated its anti-allergic inflammation using RBL-2H3 cells.

As the principal mediator in allergy, histamine affords considerable influence on allergy symptoms. Stimulation with $\operatorname{IgE}$ will activate mast cells and trigger the histamine release (20). Calcium is a critical factor for the degranulation of mast cells (1). Overload of intracellular calcium activated by $\operatorname{IgE}$ is an essential event linking stimulation to secretion, which results in the histamine release from mast cells (21). In current studies, irisflorentin can reduce the histamine release in RBL-2H3 cells exposed to DNP-HSA, along with the decline of calcium influx. In the progress of inflammation, NF- $\mathrm{KB}$ signaling pathway regulates transcription of cytokines including TNF- $\alpha$, IL- $1 \beta$ and IL- 6 , which are the effective mediators of a chronic inflammatory response (22). The activation of NF- $\mathrm{KB}$ for the transcription depends on its phosphorylation and translocation into the nucleus after release from the complex with $\mathrm{I} \kappa \mathrm{B} \alpha(23)$. As the prototypical and most extensively studied member of the family, degradation of I $\mathrm{B} \alpha$ via phosphorylation and ubiquitination can result in the release of NF- $\mathrm{KB}$ (7). In addition, the synthesis of IL-1 $\beta$ is from the inactive precursor pro-IL-1 $\beta$ under the catalysis of caspase- 1 , an IL- $1 \beta$ converting enzyme (24). As a member of the cysteine-aspartic acid protease family, caspase- 1 is activated through the cleavage of pro-caspase-1 (25). In response to allergens or associated molecular signals, the NLRP3 inflammasome complex will be assembled and activate caspase-1, which proteolytically cleaves other proteins including the precursor of IL-1 $\beta$ (26). Our investigation has unraveled irisflorentin can reduce the secretion of pro-inflammatory cytokines including TNF- $\alpha$, IL- $1 \beta$ and IL- 6 in RBL-2H3 cells stimulated by DNP-HSA. At the 
same time, activated $\mathrm{NF}-\kappa \mathrm{B}$, as well as upstream I $\kappa \mathrm{B} \alpha$, was suppressed. In addition, the activity of caspase-1 was inhibited by irisflorentin. These findings elucidated the anti-allergic inflammatory effects of irisflorentin were closely associated with the inactivation of NF- $\mathrm{KB}$ signaling pathway and caspase-1 activity.

\section{CONCLUSION}

In summary, our present studies have evaluated the anti-allergic inflammatory effects irisflorentin and possible mechanisms using RBL-2H3 cells exposed to DNP-HSA. Irisflorentin can reduce the histamine release via blocking calcium influx to attenuate acute allergy. The chronic inflammatory response in mast cells was ameliorated through affecting pro-inflammatory cytokines secretion, which involves suppressing activation of $N F-\kappa B$ signaling pathway and inhibiting caspase- 1 activity. These results will provide facts for the therapy of allergic diseases and the application of irisflorentin in practice.

\section{REFERENCES}

1. Galli S.J., Tsai M., Piliponsky A.M.: Nature 454, 445 (2008).

2. Galli S.J., Tsai M.: Nat. Med. 18, 693 (2012).

3. Kalesnikoff J., Galli S.J.: Chem. Immunol. Allergy 95, 45 (2010).

4. Kawakami T., Galli S.J.: Nat. Rev. Immunol. 2, 773 (2002).

5. Liu T., Zhang L., Joo D., Sun S.C.: Signal Transduct. Target. Ther. 2, e17023 (2017).

6. Tak P.P., Firestein G.S.: J. Clin. Invest. 107, 7 (2001).

7. Hayden M.S., Ghosh S.: Cell Res. 21, 223
(2011).

8. Hayden M.S., Ghosh S.: Cell 132, 344 (2008).

9. Liu M., Yang S., Jin L., Hu D., Wu Z., Yang S.: Molecules 17, 6156 (2012).

10. Qin M.J., Li R., Wang X., Ye W.C.: J. Integr. Plant Biol. 49, 213 (2007).

11. Chen Y.M., Liu S.P., Lin H.L., Chan M.C., Chen Y.C. et al.: BioMedicine 5, 24 (2015).

12. Gao Y., Fang L., Liu F., Zong C., Cai R. et al.: Exp. Biol. Med. 239, 1018 (2014).

13. Fu R.H., Tsai C.W., Tsai R.T., Liu S.P., Chan T.M. et al.: Cell Transplant. 24, 573 (2015).

14. Passante E., Frankish N.: Inflamm. Res. 58, 737 (2009).

15. Grimbaldeston M.A., Metz M., Yu M., Tsai M., Galli S.J.: Curr. Opin. Immunol. 18, 751 (2006).

16. Kim H.H., Bae Y., Kim S.H.: Food Chem. Toxicol. 57, 209 (2013).

17. Bae Y., Lee S., Kim S.H.: Toxicol. Applied Pharmacol. 254, 56 (2011).

18. Lee N.Y., Chung K.S., Jin J.S., Bang K.S., Eom Y.J. et al.: J. Nat. Prod. 78, 2956 (2015).

19. Zhang W.D., Yang W.J., Wang X.J., Gu Y., Wang R.: J. Chromatogr. B 879, 3735 (2011).

20. Kim H.H., Park S.B., Lee S., Kwon T.K., Shin T.Y. et al.: Toxicol. Applied Pharmacol. 274, 455 (2014).

21. Beaven M.A., Rogers J., Moore J.P., Hesketh T.R., Smith G.A., Metcalfe J.C.: J. Biol. Chem. 259, 7129 (1984).

22. Oeckinghaus A., Ghosh S.: Cold Spring Harb. Perspect. Biol. 1, a000034 (2009).

23. Hayden M.S., Ghosh S.: Cell 132, 344 (2008).

24. Thornberry N.A., Bull H.G., Calaycay J.R., Chapman K.T., Howard A.D. et al.: Nature 356, 768 (1992).

25. Singh T.S.K., Lee S., Kim H.H., Choi J.K., Kim S.H.: Toxicol. Lett. 210, 64 (2012).

26. Xiao Y., Xu W., Su W.: Clin. Exp. Allergy 48, 1080 (2018).

Received: 26.11.2018 